\title{
SeXX and COVID-19: tussle between the two
}

\author{
Ashlesh Patil ${ }^{1}$, Jaya Prasad Tripathy ${ }^{2}$, Vishwajit Deshmukh ${ }^{3}$, Bharat Sontakke ${ }^{3}$, Satyendra C. Tripathi ${ }^{4}$ \\ ${ }^{1}$ Department of Physiology; ${ }^{2}$ Department of Community Medicine; ${ }^{3}$ Department of Anatomy; ${ }^{4}$ Department of \\ Biochemistry, All India Institute of Medical Sciences, Nagpur, India
}

\begin{abstract}
Novel coronavirus disease (COVID-19) has affected nearly 7 million individuals and claimed more than 0.4 million lives to date. There are several reports of gender differences related to infection and death due to COVID-19. This raises important questions such as "Whether there are differences based on gender in risk and severity of infection or mortality rate?" and "What are the biological explanation and mechanisms underlying these differences?" Emerging evidences have proposed sex-based immunological, genetic, and hormonal differences to explain this ambiguity. Besides biological differences, women have also faced social inequities and economic hardships due to this pandemic. Several recent studies have shown that independent of age males are at higher risk for severity and mortality in COVID-19 patients. Although, susceptibility to SARS-CoV-2 was found to be similar across both genders in several disease cohorts, disproportionate
\end{abstract}

Correspondence: Satyendra C. Tripathi, Department of Biochemistry, All India Institute of Medical Sciences, Nagpur, India.

E-mail: sctripathi@aiimsnagpur.edu.in

Key words: Sex; COVID-19; SARS Cov-2; ACE2; innate immunity; adaptive immunity.

Conflict of interest: The authors have no conflict of interest to declare.

Contributions: AP was involved in conception of the idea, literature review, drafting the manuscript, editing and finalization of the manuscript; SCT, VD and JPT was involved in in conception of the idea, literature review, critical review, editing and finalization of the manuscript. BS was involved in literature review and critical review of the manuscript. All the authors gave their approval to the final submitted version of the manuscript.

Funding: None

Ethical approval: Not required.

Received for publication: 18 June 2020.

Accepted for publication: 28 August 2020.

${ }^{\circ}$ Copyright: the Author(s), 2020

Licensee PAGEPress, Italy

Monaldi Archives for Chest Disease 2020; 90:1461

doi: 10.4081/monaldi.2020.1461

This article is distributed under the terms of the Creative Commons Attribution Noncommercial License (by-nc 4.0) which permits any noncommercial use, distribution, and reproduction in any medium, provided the original author(s) and source are credited. death ratio in men can be partly explained by the higher burden of pre-existing diseases and occupational exposures among men. At immunological point of view, females can engage a more active immune response, which may protect them and counter infectious diseases as compared to men. This attribute of better immune responses towards pathogens is thought to be due to high estrogen levels in females. Here we review the current knowledge about sex differences in susceptibility, the severity of infection and mortality, host immune responses and role of sex hormones in COVID-19 disease.

\section{Introduction}

Novel coronavirus disease (COVID-19) that emerged in Wuhan China during December 2019, was declared as a pandemic by the World Health Organization (WHO) on $11^{\text {th }}$ March 2020 [1]. COVID-19 is caused by severe acute respiratory syndrome coronavirus-2 (SARS-CoV-2), a single-stranded RNA virus that belongs to the Betacoronavirus genus of Coronoviridae family [2]. As of $10^{\text {th }}$ June 2020, COVID-19 has infected more than 7 million individuals claiming 0.4 million deaths worldwide [3]. One of the key risk factors for disease and death due to COVID-19 is sex. Previous epidemics of coronaviruses such as the severe acute respiratory syndrome (SARS) and the Middle East respiratory syndrome (MERS) also reported worse clinical outcomes among the male sex [4,5]. Series of animal experiments have proven the increased susceptibility of males to SARS and MERS infections with a degree of severity further increasing with advancing age [6].

Sex disaggregated data is essential to understand sex differences in severity and mortality in the current pandemic as well. Public health policies need to address the sex impact of this pandemic so that targeted interventions can be implemented. Women seem to have a similar risk of COVID-19 infection, with conflicting evidence from different sub-groups of population and different countries. But there is consistent evidence of higher death rates recorded among men compared to women. Emerging evidence has proposed sex-based immunological and hormonal differences to explain these differences. Gendered differences, such as the prevalence of smoking and other co-morbidities also explain differences in mortality.

These sex-based differences in COVID-19 need a deeper understanding of the basic difference between the two sexes. Herein, we have comprehensively reviewed the scientific literature on sex differences in COVID-19, in terms of their epidemiological, immunological, and hormonal responses. Moreover, implications of the immune differences between both the sexes on vaccine and other treatment modalities have also been discussed. 


\section{Sex differences in COVID-19: susceptibility,} severity and mortality

Several recent studies have shown that gender is a risk factor for severity and mortality in patients with COVID-19, especially the male gender, independent of age (Figures 1 and 2). The number of men is 2.4 times that of women in the deceased patients [7]. In six countries (China, France, Germany, Iran, Italy, South Korea) reporting mortality by sex, the proportion of deaths among confirmed cases is higher in men than women, the difference is greater than $50 \%$ in four of these countries (China, Italy, France and South Korea). An observational study from Wuhan found that males over the age of 50 years with non-communicable diseases are at highest risk of dying from COVID-19 [8]. However, many countries have not yet released their sex-disaggregated data, especially country like the United States of America having the highest number of cases in the world.

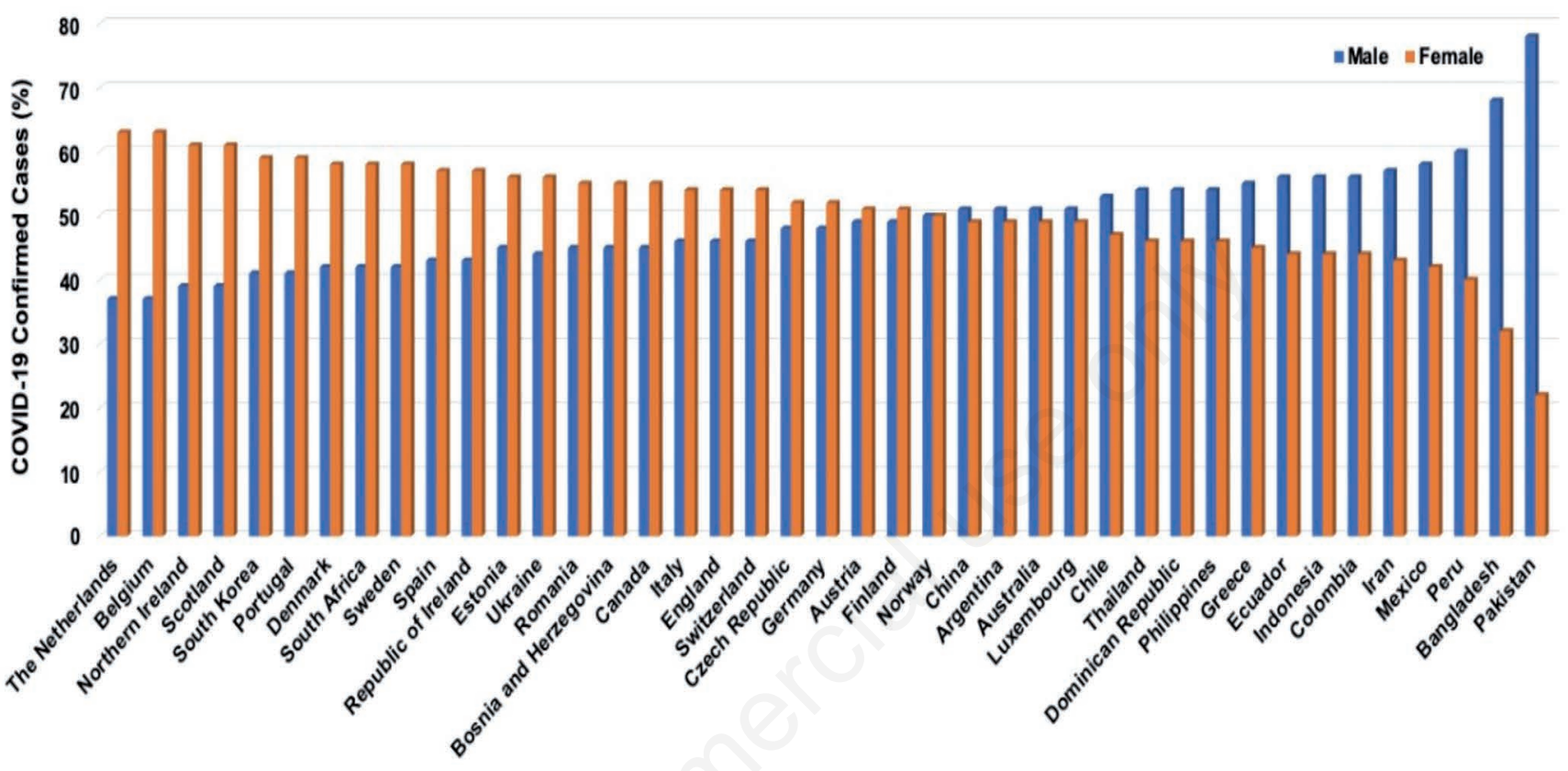

Figure 1. Sex differences in COVID-19 cases across different countries. Source: Global Health 50/50 (https://globalhealth5050.org/covid19/)

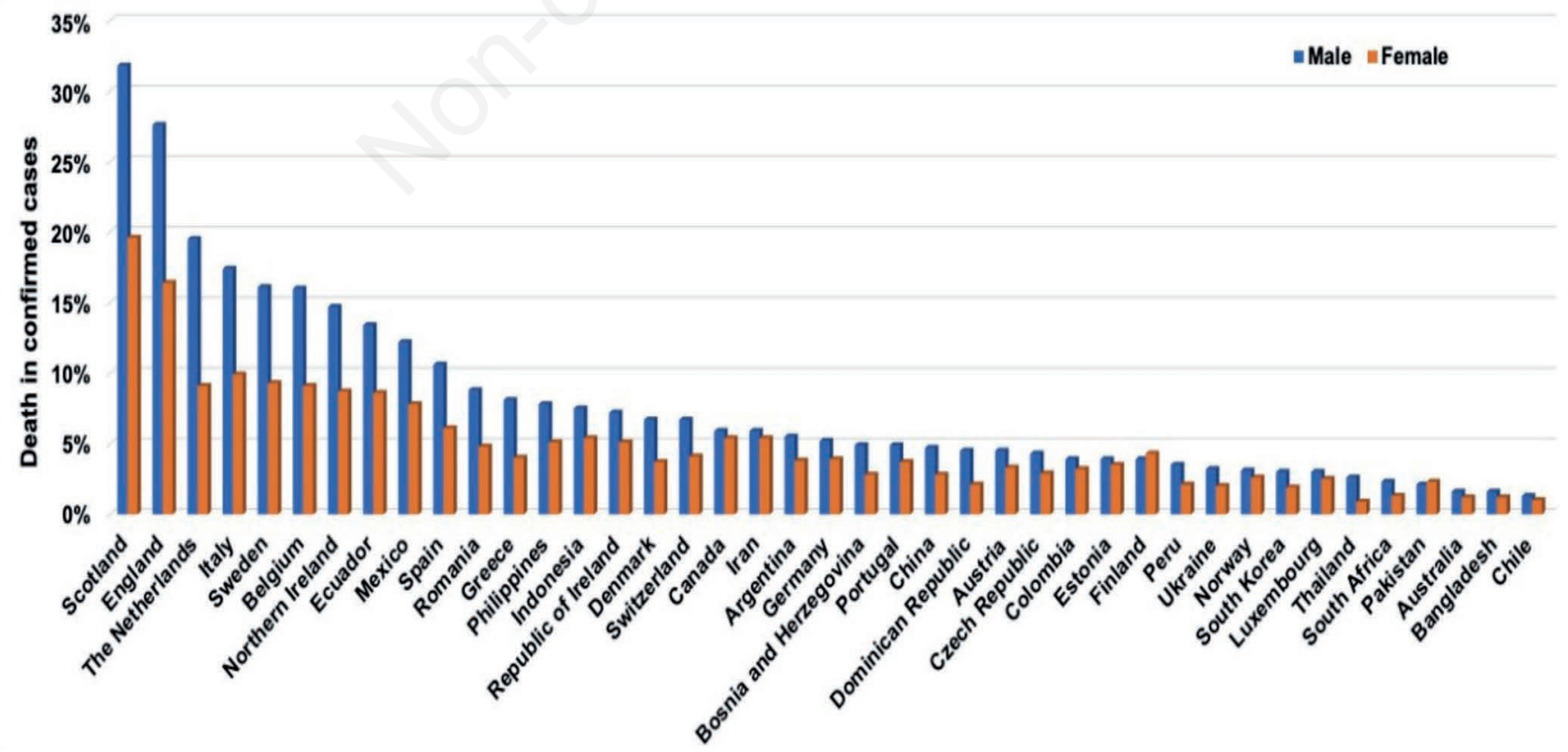

Figure 2. Sex differences in COVID-19 mortality across different countries. Source: Global Health 50/50 (https://globalhealth5050.org/covid19/). 
This disproportionate death ratio in men can be partly explained by the higher burden of pre-existing diseases (i.e., hypertension, diabetes, and chronic lung disease), higher risk behaviors (i.e., smoking and alcohol use), and occupational exposure among men $[9,10]$. Behavioral and social differences suggesting that women are more likely than men to follow hand-hygiene practices and seek preventive care are believed to be protective for women [11,12] Previous epidemics of coronaviruses such as the severe acute respiratory syndrome (SARS) in Hong Kong and the Middle East respiratory syndrome (MERS) also reported worse clinical outcomes among the male sex. Coronaviruses including SARS-CoV-2 seem to less commonly affect children and cause fewer symptoms and less severe disease in this age group compared with adults, and are associated with much lower case-fatality rates [13]. However, gender disaggregated data is limited in this age group. Besides severity and mortality, susceptibility to SARS-CoV-2 was found to be similar across both gender in several disease cohorts [7,9]. These differences in susceptibility, severity and mortality across gender could be attributed to immunological, hormonal and genetic differences which have been explained below $[14,15]$.

If we look at the social aspect, women tend the bear the brunt of the pandemic. Women form a large share of the health care sector, and as home and family caregivers, which makes them more exposed to the virus. Inequities disproportionately affect the wellbeing and economic resilience of the female sex during lockdown. Also, the complete shift in the priorities of the health system in addressing this pandemic has disrupted key health services for women and girls, such as reproductive and sexual health services. Pregnant women can be particularly vulnerable in this context. With strained economic resources, girls are likely to be deprived of education. Women are likely to experience a significant burden of household work including child care, elderly care and care of the sick. An increase in gender-based violence (and its severity and frequency) due to confinement has been observed across countries [16].

\section{SARS-CoV-2 infection and host responses}

Most of the viral infections are tackled well by the host immune system. However, some viral properties allow the infection to persist in the host. The knowledge of viral structure and genome is essential to understand these aspects of virology. Like other betacoronaviruses, SARS-CoV-2 has an outer envelope encapsulating the viral genome (Figure 3a). Genomic analysis has shown that SARS-CoV-2 has $79.6 \%$ sequence identity to SARS$\mathrm{CoV}$ and $96 \%$ identity with bat coronavirus (BatCoV RaTG13) $[17,18]$. The viral genome encodes for replicase and viral structural proteins like spike protein $(\mathrm{S})$, nucleocapsid $(\mathrm{N})$, membrane protein $(\mathrm{M})$, and envelope protein (E). Life cycle of SARS-cov2 in the host involves five steps: viral binding/entry, fusion, translation, assembly and release [19]. Viral entry into the host cell is mediated

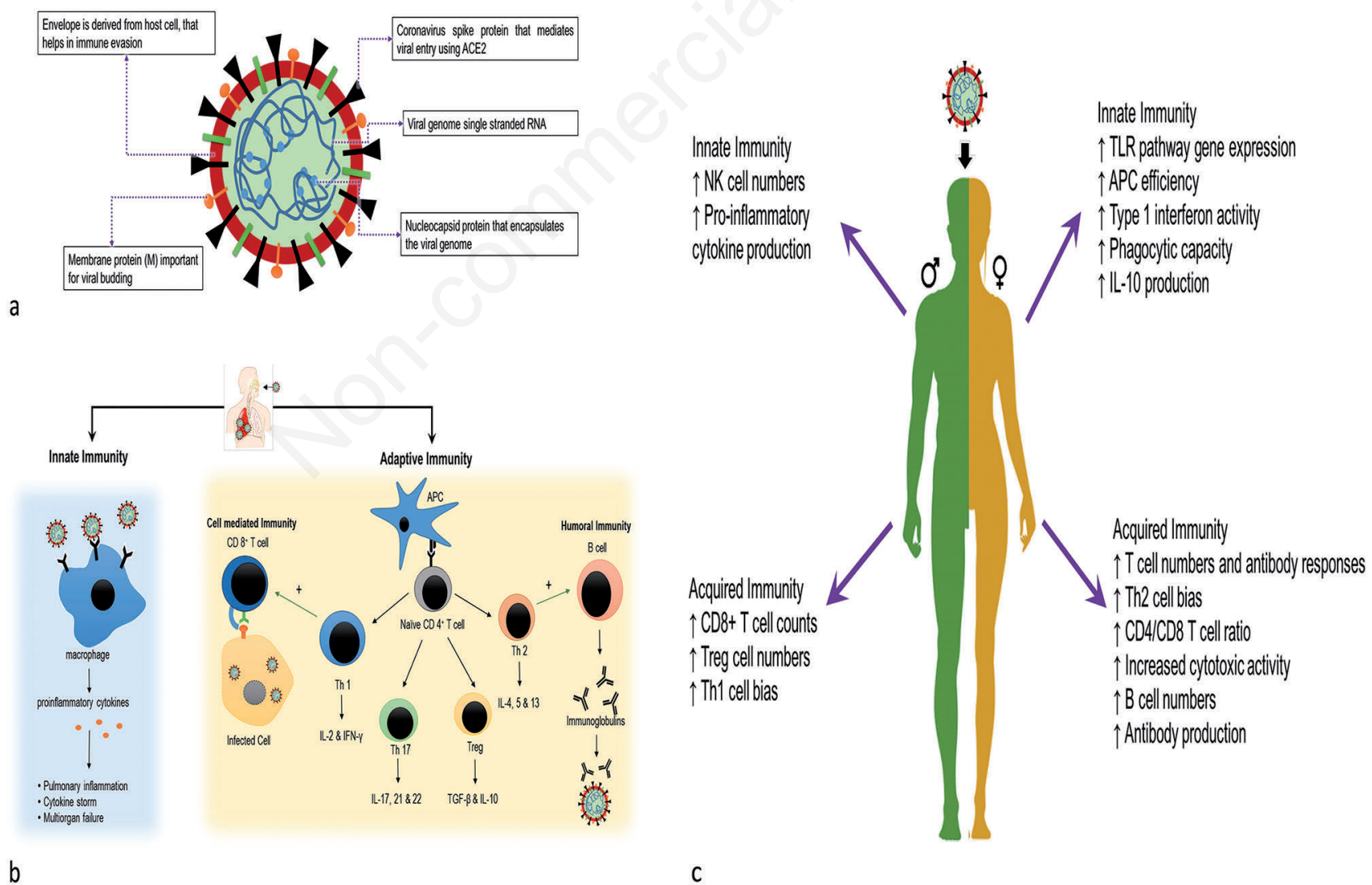

Figure 3. a) Diagrammatic representation of the structure of SARS CoV; SARS CoV-2 has outer envelope encapsulating the viral genome. Spike and membrane protein are embedded in the envelope. b) Immunes responses to COVID-19; decreased T cell count and uninhibited proinflammatory response is seen in severe disease. c) Gender biased immunity in COVID-19: females have better immune responses to viral infection and the Th2 bias reduces the pro-inflammatory cytokines. 
by spike glycoprotein (S) that is embedded in the capsule. S protein has two subunits $\mathrm{S} 1$ and $\mathrm{S} 2$. The $\mathrm{S} 1$ subunit has a receptor binding domain (RBD) which attaches to ACE2 on the host cell [20]. Indeed, SARS CoV-2 has 10 times more affinity for ACE2 receptor than SARS- CoV [21] and the expression of ACE2 in epithelial cells of lung explains the lung damage seen in severe COVID-19 infection [22]. A cellular serine protease TMPRSS2 and endosomal cysteine proteases cathepsin B and L expressed on host cells mediates $\mathrm{S}$ protein priming [23]. This interaction triggers a conformational change in $\mathrm{S}$ protein that helps in endocytosis of the virus [23]. S2 subunit helps in membrane fusion and release of viral RNA into the cytoplasm [20]. The viral genome translates replicase polyproteins that subsequently get cleaved and assembled with other cellular proteins to form replicase transcriptase complex [24]. The complex helps in viral protein translation followed by viral assembly and release. Subsequently the mature viruses are released into the host system leaving behind a pyroptotic cell that triggers an immune mechanism in the host body [25].

The COVID-19 infection can be divided in different stages: Stage 1 (asymptomatic), Stage 2 (upper airway and conducting airway response) and Stage 3 (hypoxia, ground glass infiltrates, and progression to ARDS) [26]. Low pathogenic strains of SARSCoV-2 cause mild upper respiratory infection while highly pathogenic strains cause severe infection especially in patients with impaired immune system [27]. The immune response to COVID19 is divided in two phases. During Phase 1, specific adaptive immunity helps in elimination of virus in early and mild cases. Phase 2 is seen in severe cases where damaged pyroptotic cells induce pulmonary inflammation mediated by pro-inflammatory cells and subsequent cytokine storm that may also lead to multiorgan failure [28]. Innate immunity detects viral components through pattern recognition receptors (PRRs) like toll like receptors (TLRs), retinoic acid inducible genes like receptors (RLRs), NOD like receptors (NLRs) and cytosolic DNA sensors [29]. TLRs and RLRs are responsible for the production of Type 1 Interferon, proinflammatory cytokines and chemokines and stimulates the production of CD40, CD80 and CD86 [30]. Recognition of SARSCoV-2 proteins by TLRs leads to release of proinflammatory cytokines like interleukin (IL)-1 $\beta$ and IL-6. TLR7 and TLR8 recognizes ssRNA while TLR 2 mediates recognition of $\mathrm{S}$ protein $[31,32]$. NLRs are responsible for production of Interleukin-1 Beta, through the activation of caspase-1 [33]. Type 1 interferons and complement proteins help in limiting the spread of virus during early stages of infection. IFNs- $\alpha / \beta$ thus are ideal candidates for antiviral therapy in viral infection like COVID-19 [34]. Indeed, inhaled IFN- $\alpha 2 b$ therapy has been shown to reduce duration of viral shedding and inflammatory markers IL-6 and CRP in COVID-19 [35]. In case, if viral replication outpaces innate immunity, the second line of defense "adaptive immunity" comes into play. Adaptive immune response mainly consists in antibody-producing $\mathrm{B}$ cells and cytotoxic $\mathrm{T}$ cells that destroy virus-infected cells. Increased neutrophil-to-lymphocyte ratio and marked lymphopenia with decreased $\mathrm{T}$ cells have been documented in severe COVID-19 [36]. Thus, SARS CoV-2 damages the T lymphocytes impairing the adaptive immune response while the dysregulated innate immune response leads to excessive inflammation and cytokine storm [36]. Proinflammatory cytokines like IL2, IL 6, IL8, IL10, GCSF, IP10, MCP1, MIP1A, and TNF $\alpha$ are increased in COVID-19 cases [37]. IL 6 and IL 10 upregulate expression of NK group 2 member A (NKG2A) receptor while IL 6 and 8 impair NK cells function $[38,39]$. Further, enhanced NKG2A expression functionally exhausts CD8+ cells and NK cells in severe cases leading to severely compromised innate immune response [40].

\section{Gender biased immunity and COVID 19}

The sex-wise demographics across the world depicts that in some countries, males are more susceptible to COVID-19 than females, while females are more infected than males in other countries (Figure 2a) [9,41]. Many countries (Scotland, England, Netherland, Italy, Sweden, Belgium) have reported higher mortality rate in men as compared to women among the confirmed cases of COVID-19 (Figure 2b). Prevalence and severity of viral infections differs depending upon biological factors like age, sex and immune status. Sexual dimorphism forms the basis for variant anatomical, physiological and immunological responses. Sex differences in disease outcomes following virus infections could be attributed to X-linked genes, production of sex-dependent steroid hormones, and the presence of disease susceptibility genes in males and females [14].

$\mathrm{X}$-chromosome contains a high density of immune-related genes; therefore, women generally mount stronger innate and adaptive immune responses than men [42]. X chromosome contains largest number of genes that regulate immune system. Females have advantage of having $2 \mathrm{X}$ chromosomes offering them 2 allelic options for these genes. Mosaicism due to X inactivation also offers immune advantage to female over males [43]. Indeed, $\mathrm{X}$ chromosomal variation has been shown to increase the survival in HIV infection [44]. While genetic variation in Y chromosome is involved in susceptibility of males to viral infection [45]. X chromosome inactivation in females is not uniform across all the immune cells and there are chances of bi-allelic expression of genes. Since the X chromosomes comes from different parent it offers more immune diversity in females as compared to males [43]. This results in faster clearance of pathogens but also contributes to their increased susceptibility to inflammatory and autoimmune diseases.

The rule of 'sexual dimorphism' is followed by both innate and acquired immunity. It has been identified that male gender is more prone to all infections such as bacterial, viral and fungal. The increased infection rates with reduced immune response in males is probably a side effect of sex-specific positive selection process that gives more weightage to reproductive functions than immunity [46]. In one study related to HIV infection, it was identified that viral load in females is $40 \%$ less as compared to males [47]. Females tend to have higher innate and adaptive immune responses to viral infection [48]. Females have lower levels of IL-8 and C-X-C motif chemokine 10 (CXCL10) than males during an acute viral infection [49]. These chemokines attract cells like neutrophils, macrophages, T cells, NK cells, and dendritic cells at the infected site further augmenting the immune response. High levels of CXCL10 are seen in severe COVID-19 cases with lung damage [50]. Furthermore, anti IL8 therapy trial is been tried as treatment modality for COVID-19 [51]. Higher levels of IL 6, a pro inflammatory cytokine linked with exacerbation of viral disease, in seen males as compared to female mice following lipopolysaccharide challenge [52]. Thus, using tocilizum$\mathrm{ab}$ an IL6 receptor blocker can be beneficial in reducing severity in COVID-19 [53]. Innate immunity of a male and a female are very different suggesting a germline evolution. For example, TLR7 has lower gene expression in males than females [54]. This results in increased IFN $\alpha$ production following exposure to TLR7 ligands in women compared to men $[55,56]$. Previous reports have also suggested that gene expression related to TLR or inflammatory pathway are always higher in females than males, which suggest that females are much more capable or stronger to combat the infectious diseases $[57,58]$ Previous research has also revealed that men have lower 
innate antiviral immune responses to a range of infections including hepatitis C and HIV [48] Antigen presentation efficiency of females are far much better than their counterparts [14] Except for natural killer (NK) cells, females also have highly active macrophages and neutrophils [59]. Females exhibit higher expression of TLRs 3, 7 and 9 which can recognise viral RNA or DNA [54,60]. However, TLRs 2 and 4 which have higher expression in males, only attach to bacterial cell wall proteins $[61,62]$. These dimorphic innate immune responses can certainly be attributed to different sex steroids [57].

Similar to innate immunity, adaptive immunity also is influenced by gender (Figure $3 \mathrm{~b}, \mathrm{c}$ ). Females tend to have a higher number of $\mathrm{T}$ helper cells as compared to males who have increased counts of cytotoxic $\mathrm{T}$ cells [63]. Moreover, after stimulation women produce larger quantities of activated CD4+ and CD8+ T cells $[64,65]$. Previous studies have also observed an increased expression of antiviral (such as IFNG, SPINK5 and RIGI) and proinflammatory (IL16, IL1F5 and CXCL2) genes in females compared to males [66]. Notably, various lymphoid tissue cells, lymphocytes, macrophages, and DCs express estrogen receptors. Antibody responses of females are also better than males as they have a higher number of $\mathrm{B}$ cells and increased basal levels of immunoglobulins [64,67,68]. Females generally exhibit higher Th2 response to viral infection as compared to males [63]. Thus, by mounting an effective adaptive response at the same time limiting the pro-inflammatory mediators protects the females from developing severe disease.

\section{Role of sex hormones in COVID-19}

Sex hormones also play a vital role in regulation of immune response to infection. Male sex hormone i.e. testosterone has immunosuppressive effects, on the contrary the estrogen (female sex hormone) is known for its immunoenhancing effect [69]. Such differential regulation of immunity by sex hormones provides an evolutionary advantage for survival during reproductive years. Estrogen receptors are expressed on various immune cells like dendritic cells, macrophages, B and T lymphocytes. The two subtypes of estrogen receptors ER-alpha and ER-beta are differential expressed on $\mathrm{T}$ and $\mathrm{B}$ cells respectively. Estrogen via its surface receptors has been shown to be influence the downstream signaling pathways of innate immunity ad adaptive immunity. Various experiments on mice models suggest that estrogen signaling protects female mice from severe/fatal forms of infection [6]. Estrogen increased the activity of NK cells and in high doses reduces the secretion of pro-inflammatory cytokines from monocytes and macrophages [69]. Estrogens inhibits the production of Th1 mediated proinflammatory cytokines and stimulates the production of Th2 mediated anti-inflammatory cytokines [70]. Furthermore, varying levels of estrogen during menstrual phase also influence immune response with shift towards Th2-type response seen during luteal phase [71]. Low levels of estrogen during menstruation enhances the activity of proinflammatory cytokines while increased levels of estrogen during follicular phase suppresses these cytokines [71]. Estrogen treatment has been shown to reduce the inflammatory reaction and decrease viral load. Thus, conjugate estrogens that have similar action to endogenous estrogen provide a promising therapy option for both gender in COVID-19 [72]. Estrogen also helps in B cell development and antibody response to infection. Several genes required for B cell activation and survival are up regulated by estrogen [73]. High levels of estrogen just before ovulation positively correlates with $\mathrm{B}$ cells count and antibody levels [74]. Thus, estrogen in post pubertal females provides an added advantage in reducing unwarranted inflammation during acute viral infections.

Since both immunity and reproduction are energy consuming processes the nature has decided to be sex biased with males utilizing more resources for reproduction than immunity. High levels of testosterone and dihydrotestosterone levels in post pubertal males are generally immunosuppressant in mammals. Androgens mediate immunosuppression by reducing the activity of NK cells and macrophages. Testosterone decreases pro-inflammatory cytokine mediators while increasing the anti-inflammatory mediators like IL-10 and transforming growth factor $\beta$ (TGF $\beta$ ) [75]. A recent study found that most of the critical ill COVID 19 patients suffer from testosterone and dihydrotestosterone deficiencies [76]. Thus, the immunosuppressant effects of androgens are reduced in severe cases. Indeed, low levels of testosterone are linked with increased level of inflammatory cytokines, reduced $\mathrm{T}$ regulatory cells and increased NK cell activity [75]. Moreover, testosterone therapy has been shown to improve the survival rate in young gonadectomized male mice infected with influenza [77]. However, such therapy does not alter the viral replication or pulmonary pathology. Since, androgen receptor activity is important is regulation of TMPRSS2 and also for ACE 2, receptors that helps in SARS-Cov2 entry into the host cell $[78,79]$. Low testosterone levels lead to up regulation of androgen receptors that may augment the expression of ACE2 and TMPRSS2 receptors on host cells.

\section{Implication of gender differences on COVID-19 vaccine and treatment modalities}

Sex and gender have an important role to play in vaccine responses and outcomes [58]. Females, once vaccinated, develop higher antibody responses to vaccines than males. Vaccination against influenza, yellow fever, rubella, measles, mumps, hepatitis $\mathrm{A}$ and $\mathrm{B}$, herpes simplex 2, rabies, smallpox, and dengue viruses have reported protective antibody responses twice as high in adult females than in males [58]. Cell-mediated immunity following vaccination are also higher in females than in males for some vaccines [80,81]. Females also develop more frequent and severe adverse reactions due to enhanced immune activation and inflammatory responses to vaccines compared to their male counterparts $[58,68]$. Because reporting of adverse events following vaccination is often done via passive reporting, it is also believed that differences in reporting might reflect a gender difference, in which females might be more likely than males to report adverse side effects. Sex and gender also interact to alter vaccine responses and outcomes by affecting exposures to microbial infection, our diet, and even the composition of our microbiome, each of which can affect vaccine responses and efficacy [82]. Thus, men and women tend to react differently to potential vaccines and treatments, so having access to sex-disaggregated data is crucial for conducting safe clinical/vaccine trials.

Potential immunotherapy like plasma therapy, specific immunoglobulins, thymosin and tocilizumab are widely being used or tested for COVID-19. However, given the differential immune response and related severity in both the sexes, sex-disaggregated data needs to be collected for these immunotherapy to better understand COVID-19 immunopathology. The primary drug being used to treat COVID-19 patients is hydroxychloroquine (HCQ) which works by suppressing immunity. We know that men and women differ in their immune responses, but we don't know 
how sex differences influence the efficacy of HCQ, or whether sex-specific dosing might produce fewer side effects and more positive outcomes. This calls for further research.

\section{Conclusions}

The immune response for any foreign pathogen is different among male and females. Evolutionary selection has given an immunological advantage to females promoting their survival in adversity. The observed sex differences in severity against viral infection can be attributed to immune variation due to $\mathrm{X}$ chromosome, production of sex-dependent steroid hormones, and variation in prevalence of co-morbidities. Females are protected from developing a severe viral infection by mounting an effective innate and acquired immune response while at the same time limiting the pro-inflammatory cytokines. Estrogen and its cyclic variation during the menstrual cycle helps in maintaining an immune-enhanced state during viral infection; while low testosterone levels in males fail to suppress the cytokine storm. Vaccine and immunotherapy for COVID-19 need to consider these sex-based immune differences and there is urgent need of in-depth research studies to understand the sex-bias observed in coronavirus infections.

\section{References}

1. Cucinotta D, Vanelli M. WHO Declares COVID-19 a Pandemic. Acta Biomed 2020;91:157-60.

2. Coronaviridae Study Group of the International Committee on Taxonomy of Viruses. The species Severe acute respiratory syndrome-related coronavirus: classifying 2019-nCoV and naming it SARS-CoV-2. Nat Microbiol 2020;5:536-44.

3. WHO. COVID-19 situation reports. Accessed on: June 11, 2020. Available from: https://www.who.int/emergencies/diseases/novel-coronavirus-2019/situation-reports

4. Karlberg J, Chong DSY, Lai WYY. Do men have a higher case fatality rate of severe acute respiratory syndrome than women do? Am J Epidemiol 2004;159:229-31.

5. Alghamdi IG, Hussain II, Almalki SS, et al. The pattern of Middle East respiratory syndrome coronavirus in Saudi Arabia: a descriptive epidemiological analysis of data from the Saudi Ministry of Health. Int J Gen Med 2014;7:417-23.

6. Channappanavar R, Fett C, Mack M, et al. Sex-based differences in susceptibility to SARS-CoV infection. J Immunol 2017; 198:4046-53.

7. Jin JM, Bai P, He W, et al. Gender differences in patients with COVID-19: Focus on severity and mortality. Front Public Health 2020;8. doi.org/10.3389/fpubh.2020.00152.

8. Du Y, Tu L, Zhu P, et al. Clinical features of 85 fatal cases of COVID-19 from Wuhan. A retrospective observational study. Am J Respir Crit Care Med 2020;201:1372-9.

9. Global Health 50/50 [Inteernet]. Sex, gender and COVID-19: overview and resources. Accessed on: May 8, 2020. Available from: https://globalhealth5050.org/covid19/

10. Antonello RM, Dal Bo E, De Cristofaro P, et al. The seXY side of COVID-19: what is behind female protection? Infez Med 2020;28:288-9.

11. Bertakis KD, Azari R, Helms LJ, et al. Gender differences in the utilization of health care services. J Fam Pract 2000;49:147-52.

12. Johnson HD, Sholcosky D, Gabello K, et al. Sex differences in public restroom handwashing behavior associated with visual behavior prompts. Percept Mot Skills 2003;97:805-10.

13. Zimmermann P, Curtis N. Coronavirus infections in children including COVID-19: An overview of the epidemiology, clinical features, diagnosis, treatment and prevention options in children. Pediatr Infect Dis J 2020;39:355-68.

14. Weinstein Y, Ran S, Segal S. Sex-associated differences in the regulation of immune responses controlled by the $\mathrm{MHC}$ of the mouse. J Immunol 1984;132:656-61.

15. Robinson DP, Huber SA, Moussawi M, et al. Sex chromosome complement contributes to sex differences in coxsackievirus B3 but not influenza A virus pathogenesis. Biol Sex Differ 2011;2:8.

16. Wenham C, Smith J, Morgan R. COVID-19: the gendered impacts of the outbreak. Lancet 2020;395:846-8.

17. Zhou P, Yang X-L, Wang X-G, et al. A pneumonia outbreak associated with a new coronavirus of probable bat origin. Nature 2020;579:270-3.

18. Deshmukh V, Tripathi SC, Pandey A, et al. COVID-19: a conundrum to decipher. Eur Rev Med Pharmacol Sci 2020;24:5830-41.

19. Shereen MA, Khan S, Kazmi A, et al. COVID-19 infection: Origin, transmission, and characteristics of human coronaviruses. J Adv Res 2020;24:91-8.

20. Tay MZ, Poh CM, Rénia L, et al. The trinity of COVID-19: immunity, inflammation and intervention. Nat Rev Immunol 2020:1-12.

21. Wrapp D, Wang N, Corbett KS, et al. Cryo-EM structure of the 2019-nCoV spike in the prefusion conformation. Sci 2020:367:1260-3.

22. Hamming I, Timens W, Bulthuis M, et al. Tissue distribution of ACE2 protein, the functional receptor for SARS coronavirus. A first step in understanding SARS pathogenesis. J Pathol 2004;203:631-7.

23. Hoffmann M, Kleine-Weber H, Schroeder S, et al. SARS-CoV2 cell entry depends on ACE2 and TMPRSS2 and is blocked by a clinically proven protease inhibitor. Cell 2020;181:271280.e8.

24. Sawicki SG, Sawicki DL, Younker D, et al. Functional and genetic analysis of coronavirus replicase-transcriptase proteins. PLoS Pathog 2005;1:e39. Correction in: PLOS Pathog 2:e17. https://doi.org/10.1371/journal.ppat.0020017.

25. Tang D, Comish P, Kang R. The hallmarks of COVID-19 disease. PLOS Pathog 2020;16:e1008536.

26. Mason RJ. Pathogenesis of COVID-19 from a cell biology perspective. Eur Res J 2020;55:2000607.

27. Conti P, Ronconi G, Caraffa A, et al. Induction of pro-inflammatory cytokines (IL-1 and IL-6) and lung inflammation by Coronavirus-19 (COVI-19 or SARS-CoV-2): anti-inflammatory strategies. J Biol Regul Homeost Agents 2020;34:327-31.

28. Shi Y, Wang Y, Shao C, et al. COVID-19 infection: the perspectives on immune responses. Cell Death Differ 2020;27:1451-4.

29. Thompson MR, Kaminski JJ, Kurt-Jones EA, Fitzgerald KA. pattern recognition receptors and the innate immune response to viral infection. Viruses 2011;3:920-40.

30. Sallard E, Lescure F-X, Yazdanpanah Y, et al. Type 1 interferons as a potential treatment against COVID-19. Antiviral Research 2020;178:104791.

31. Heil F, Hemmi H, Hochrein H, et al. Species-specific recognition of single-stranded RNA via toll-like receptor 7 and 8 . Science 2004;303:1526-9.

32. Dosch SF, Mahajan SD, Collins AR. SARS coronavirus spike 
protein-induced innate immune response occurs via activation of the NF- $\mathrm{KB}$ pathway in human monocyte macrophages in vitro. Virus Res 2009;142:19-27.

33. Kaneko N, Kurata M, Yamamoto T, et al. The role of interleukin-1 in general pathology. Inflamm Regen 2019;39:12.

34. Wang BX, Fish EN. Global virus outbreaks: Interferons as 1st responders. Semin Immunol 2019;43:101300.

35. Zhou Q, Chen V, Shannon CP, et al. Interferon- $\alpha 2$ b Treatment for COVID-19. Front Immunol 2020;11:1061

36. Qin C, Zhou L, Hu Z, et al. Dysregulation of immune response in patients with COVID-19 in Wuhan, China. Clin Infect Dis 2020;7:762-8.

37. Huang C, Wang Y, Li X, et al. Clinical features of patients infected with 2019 novel coronavirus in Wuhan, China. Lancet 2020;395:497-506.

38. Cho JH, Kim HO, Webster K, et al. Calcineurin-dependent negative regulation of $\mathrm{CD} 94 / \mathrm{NKG} 2 \mathrm{~A}$ expression on naive CD8+ T cells. Blood 2011;118:116-28.

39. Wu J, Gao F-X, Wang C, et al. IL-6 and IL- 8 secreted by tumour cells impair the function of NK cells via the STAT3 pathway in oesophageal squamous cell carcinoma. J Exp Clin Cancer Res 2019;38:321.

40. Antonioli L, Fornai M, Pellegrini C, Blandizzi C. NKG2A and COVID-19: another brick in the wall. Cell Mol Immunol 2020;17:672-4.

41. The Lancet. The gendered dimensions of COVID-19. Lancet 2020;395:1168.

42. Schurz H, Salie M, Tromp G, et al. The X chromosome and sex-specific effects in infectious disease susceptibility. Hum Genomics 2019;13:2.

43. Libert C, Dejager L, Pinheiro I. The X chromosome in immune functions: when a chromosome makes the difference. Nature Reviews Immunology 2010;10:594-604.

44. Siddiqui RA, Sauermann U, Altmüller J, et al. X chromosomal variation is associated with slow progression to AIDS in HIV1-infected women. Am J Hum Genet 2009;85:228-39.

45. Krementsov DN, Case LK, Dienz O, et al. Genetic variation in chromosome Y regulates susceptibility to influenza A virus infection. Proc Natl Acad Sci USA 2017;114:3491-6.

46. Restif $\mathrm{O}$, Amos W. The evolution of sex-specific immune defences. Proc Biol Sci 2010;277:2247-55.

47. Addo MM, Altfeld M. Sex-based differences in HIV type 1 pathogenesis. J Infect Dis 2014;209:S86-92.

48. Klein SL. Sex influences immune responses to viruses, and efficacy of prophylaxis and therapeutic treatments for viral diseases. Bioessays 2012;34:1050-9.

49. Klingström J, Lindgren T, Ahlm C. Sex-dependent differences in plasma cytokine responses to hantavirus infection. Clin Vaccine Immunol 2008; 15:885-7.

50. Vaninov N. In the eye of the COVID-19 cytokine storm. Nature Rev Immunol 2020;20:277.

51. ClinicalTrials.gov [Internet]. 2020 April 15. Identifier: NCT04347226. Anti-Interleukin-8 (Anti-IL-8) for patients with COVID-19. ClinicalTrials.gov Accessed on: June 7, 2020. Available from: https:/clinicaltrials.gov/ct2/show/NCT043 47226

52. Queen AE, Moerdyk-Schauwecker M, McKee LM, et al. Differential expression of inflammatory cytokines and stress genes in male and female mice in response to a lipopolysaccharide challenge. PLoS One 2016;11:e0152289.

53. Luo P, Liu Y, Qiu L, et al. Tocilizumab treatment in COVID19: A single center experience. J Med Virol 2020:92:814-8.

54. Pisitkun P, Deane JA, Difilippantonio MJ, et al. Autoreactive B cell responses to RNA-related antigens due to TLR7 gene duplication. Sci 2006;312:1669-72.

55. Berghöfer B, Frommer T, Haley G, et al. TLR7 ligands induce higher IFN-alpha production in females. J Immunol 2006;177:2088-96.

56. Griesbeck M, Ziegler S, Laffont S, et al. Sex differences in plasmacytoid dendritic cell levels of IRF5 drive higher IFN- $\alpha$ production in women. J Immunol 2015;195:5327-36.

57. Hannah MF, Bajic VB, Klein SL. Sex differences in the recognition of and innate antiviral responses to Seoul virus in Norway rats. Brain Behav Immun 2008;22:503-16.

58. Klein SL, Jedlicka A, Pekosz A. The Xs and Y of immune responses to viral vaccines. Lancet Infect Dis 2010;10:338-49.

59. Spitzer JA. Gender differences in some host defense mechanisms. Lupus 1999;8:380-3.

60. Kikkert M. Innate immune evasion by human respiratory RNA viruses. J Innate Immun 2020;12:4-20.

61. Martínez-García MÁ, Ojeda-Ojeda M, Rodríguez-Martín E, et al. TLR2 and TLR4 surface and gene expression in white blood cells after fasting and oral glucose, lipid and protein challenges: Influence of obesity and sex hormones. Biomolecules 2020;10:111.

62. Rettew JA, Huet-Hudson YM, Marriott I. Testosterone reduces macrophage expression in the mouse of toll-like receptor 4 , a trigger for inflammation and innate immunity. Biol Reprod 2008;78:432-7.

63. Uppal SS, Verma S, Dhot PS. Normal values of CD4 and CD8 lymphocyte subsets in healthy Indian adults and the effects of sex, age, ethnicity, and smoking. Cytometry B Clin Cytom 2003;52:32-6.

64. Abdullah M, Chai PS, Chong MY, et al. Gender effect on in vitro lymphocyte subset levels of healthy individuals. Cell Immunol 2012;272:214-9.

65. Sankaran-Walters S, Macal M, Grishina I, et al. Sex differences matter in the gut: effect on mucosal immune activation and inflammation. Biol Sex Differ 2013;4:10.

66. Hewagama A, Patel D, Yarlagadda S, et al. Stronger inflammatory/cytotoxic T-cell response in women identified by microarray analysis. Genes Immun 2009;10:509-16.

67. Fan H, Dong G, Zhao G, et al. Gender differences of B cell signature in healthy subjects underlie disparities in incidence and course of SLE related to estrogen. J Immunol Res 2014;2014:814598.

68. Furman D, Hejblum BP, Simon N, et al. Systems analysis of sex differences reveals an immunosuppressive role for testosterone in the response to influenza vaccination. Proc Natl Acad Sci USA 2014;111:869-74.

69. Taneja V. Sex hormones determine immune response. Front Immunol 2018;9:1931.

70. Salem ML. Estrogen, a double-edged sword: modulation of TH1- and TH2-mediated inflammations by differential regulation of TH1/TH2 cytokine production. Curr Drug Targets Inflamm Allergy 2004;3:97-104.

71. Faas M, Bouman A, Moesa H, et al. The immune response during the luteal phase of the ovarian cycle: a Th2-type response? Fertil Steril 2000;74:1008-13.

72. Suba Z. Prevention and therapy of COVID-19 via exogenous estrogen treatment for both male and female patients. J Pharm Pharm Sci 2020;23:75-85.

73. Grimaldi CM, Cleary J, Dagtas AS, et al. Estrogen alters thresholds for B cell apoptosis and activation. J Clin Invest 2002;109:1625-33.

74. Lü FX, Abel K, Ma Z, et al. The strength of B cell immunity 
in female rhesus macaques is controlled by CD8+ T cells under the influence of ovarian steroid hormones. Clin Exp Immunol 2002;128:10-20.

75. Trigunaite A, Dimo J, Jørgensen TN. Suppressive effects of androgens on the immune system. Cell Immunol 2015;294: 87-94.

76. Schroeder M, Tuku B, Jarczak D, et al. The majority of male patients with COVID-19 present low testosterone levels on admission to Intensive Care in Hamburg, Germany: a retrospective cohort study. MedRxiv 2020. doi: 10.1101/2020.05. 07.20073817 .

77. vom Steeg LG, Vermillion MS, Hall OJ, et al. Age and testosterone mediate influenza pathogenesis in male mice. Am J Physiol Lung Cell Mol Physiol 2016;311:L1234-44.

78. Wei X, Xiao YT, Wang J, et al. Sex differences in severity and mortality among patients with COVID-19: Evidence from pooled literature analysis and insights from integrated bioinformatic analysis. ArXiv 2020. arXiv:2003.13547v1 [qbio.PE].

79. Lin B, Ferguson C, White JT, et al. Prostate-localized and androgen-regulated expression of the membrane-bound serine protease TMPRSS2. Cancer Res 1999;59:4180-4.

80. Umlauf BJ, Haralambieva IH, Ovsyannikova IG, et al. Associations between demographic variables and multiple measles-specific innate and cell-mediated immune responses after measles vaccination. Viral Immunol 2012;25:29-36.

81. Zhang X, Castelli FA, Zhu X, et al. Gender-dependent HLADR-restricted epitopes identified from herpes simplex virus type 1 glycoprotein D. Clin Vaccine Immunol 2008;15:1436-49.

82. Flanagan KL, Fink AL, Plebanski M, Klein SL. Sex and gender differences in the outcomes of vaccination over the life course. Annu Rev Cell Dev Biol 2017;33:577-99. 